\title{
Focus Group Reports
}

The programme of this Working Conference included focus group discussions of questions posed by the Programme Committee, with the aims of contributing to the debate during the conference and of preparing a position paper of conference views on key issues. Nine Focus Groups were organized, each considering one of four proposed themes, learning, curriculum practice, teaching and organisation; from these they issued recommendations built on participants' experiences and points of views.

The following reports are the outcome of these discussions which took place over four days of deliberations interleaved with other conference activities, including a Poster session presentation of preliminary ideas and a plenary Panel discussion of interim reports. It is hoped that these reports, while serving as a means of inspiration for the future work of IFIP WG 3.1, will contribute to the thinking and planning of policy makers at all levels, and help with the formulation of future strategy in support of integration of information technology into the educational world.

\section{Focus Group: Integrating IT into learning}

\section{Participants}

Walter Burke (GB), Bas Cartingy (NL), Val Clarke (AUS), Alison Griffith (USA), Ivan Kalas (SO), Claus Möbus (D), Misericordic Nomen (E), Anthony Parra (E), Hannah Perl (IL), Anne Rasse (F), Joy Teague (AUS)

Chair: David Johnson (GB)

Rapporteurs: Qi Chen (PRC), David Squires (GB)

\section{Main issues}

The group felt that the notion of integration needed to be clarified in this context. For example, it was noted that integration could be interpreted with respect to informatics education as well as informatics in school subjects. IT includes both concepts and tools which can be used to facilitate learning in the broadest sense, being dependent on the availability of resources and the manner in which the resources are employed. Within this context the main issues discussed were: perceptions of learning, the relationship to other media, motivation to use IT in learning, and learning away from the school. 


\section{Perceptions of learning}

Learners will usually perceive the learning aims and context in their own terms, which may not be in those of the teacher or designer. For example, software is interpreted subjectively by the user, in this case, the learner. However, well defined software provides for multiple interpretations and multiple uses.

IT can be used to facilitate the transfer of control of the learning process from the teacher to the learner. Learners will learn when they choose the goals which are relevant to them.

A common feeling was that the use of software tools is very significant in an educational context. This significance is emphasised by the inclusion in some curricula of required project work which can be completed with the aid of IT tools. It was also noted that the completion of assignments with the aid of IT tools, such as DTP packages and graphics tools, also provides an impetus for students to use IT on a regular basis. The use of software tools allows an emphasis on skills, both at the level of knowledge acquisition and the development of meta-cognitive skills in an ever expanding spiral. This means that it is critical that recent developments in theories of learning should inform the design and use of educational software.

\section{Relationship to other media}

A group member commented "A school without books is only possible in a society without books. There are no signs that this kind of society is coming". It seems that in the foreseeable future the use of IT will need to be used in parallel with the use of more traditional media; a multiple-media approach as distinct from a multi-media approach in which different forms of media are interact through design as opposed to use.

\section{Motivation to use IT in learning}

The inclusion of computers in the assessment process provides a powerful motivation for learners to incorporate the use of IT in their work. The opportunity to use IT in the completion of project work provides a similar motivation, especially when learners discover that they can produce a more polished product and, in some instances, a saving of time and effort. Also, an IT based environment can be freer and more "fun". Students and teachers must be given the opportunity to recognise the benefits of IT.

\section{Learning away from the school}

Learning is not confined to the classroom or the conventional curriculum. IT has the potential for facilitating learning at home. One aspect of this is 
in distance learning of conventional curricula. A second area is where children choose to use IT to satisfy their personal needs. Two issues emerge:

- equity issues associated with home based learning;

- changes in perceptions of what constitutes appropriate learning.

If learning becomes predominantly or even partially home-based, what measures will need to be taken to ensure that all learners have the same access to hardware and software resources and local support? Is a new breed of peripatetic teachers envisaged, even if they only visit the home in an electronic form? Will the conventional perception of learning as something that has to be "worked at" be replaced by an "edutainment" perception? Will there be an even greater competition between the education system and the entertainment industry for the hearts and minds of children? In a home environment who will decide what constitutes appropriate programmes of study - learner, teacher, parent, ... What will be the role of telematics, for example, networking and electronic mail, in this context?

\section{Focus Group: Curriculum practice 1}

\section{Participants}

M. Angel De Miguel (E), Ichiro Kobayashi (J), Ard Hartsuijker (NL), Santiago Manrique Catalán (E), Herbert Moeller (D), Anton Reiter (A)

Chair: Peter Bollerslev (DK)

Rapporteurs: Yvonne Buettner-Ringier (CH), Zoraini Wati Abas (MAL)

\section{Main issues}

Many countries started IT education as a separate subject. Nowadays most countries integrate IT into the curriculum of other subjects. Some countries have a mixture of IT in education as a separate subject and integration into other subject areas.

IT integration varies between using computers as an educational tool and incorporating IT as new topics and new methods This differs from country to country and from subject to subject. The group discussed the successful integration of IT in Austria, Catalonia, Denmark and the Netherlands.

In order to integrate IT into the curriculum of school subjects, teachers and schools should have awareness, knowledge and a positive attitude 
towards IT and curriculum change. Teacher education should contribute in the realisation of the process of integration by:

- familiarising IT on the individual level and the school organisation level;

- activating the change in learning and teaching styles due to IT;

- influencing the revision of curriculum aiming at IT integration.

The focus group recommends that key decision makers and the general public be made aware of the following facilitating factors which will determine successful integration of IT into the curriculum:

- sufficient equipment;

- adequate teachers guidelines and teaching materials;

- suitable curriculum;

- qualified teachers and resource co-ordinators, consultants, technicians;

- resource centres;

- feedbacks from students, teachers, parents, schoolboard;

- incorporation into national syllabus and national examination program;

- authors integrating IT topics into their textbooks;

- international collaboration;

- vendor support.

The group is aware that, even within one country, there are great differences between planning and practice of the above mentioned facilitating factors. Constraints were also noticed such as financial limitations, overloaded curriculum and timetable, political interests and resistance to change.

In order to improve IT integration in many countries, the IFIP-UNESCO curriculum should be widely circulated to key decision makers and curriculum developers throughout the world. 


\section{Focus Group: Curriculum Practice 2}

\section{Participants}

Doug Brown (GB), Ton Ellermeyer (NL), Marta Krausova (CZ), Walter Oberschelp (D), Jim Schultz (USA)

Chairman: Gail Marshall (USA)

Rapporteurs: Georges-Louis Baron (F), Barry Blakeley (GB)

\section{Main issues}

The group was conscious of interacting with a very difficult subject, as curriculum has manifold meanings for different people and in different countries. Several dimensions need to be considered such as the ideal, the published, the taught, the evaluated and the learned curriculum. In a sense we were exploring new territory, identifying milestones or possible significant features in a future curriculum map. It was like exploring new territory and we were struck by the knowledge that Barcelona was the home port for Columbus, who was the link between the old and the new worlds; and Catalunya was the country of Abraham Cresques who charted terrae incognitae in the fifteenth century.

\section{Recommendations}

We can present here only the bare bones of a rewarding and stimulating discussion over four days, giving the main recommendations and a few concrete references provided by the group members.

Assessment: When the use of IT is an essential part of students' application of their knowledge, IT must be present in both the formative and summative aspects of the assessment process.

The group noted that SAT examinations in the USA now carry a recommendation that students will be disadvantaged if they do not make use of IT, and that French technical/vocational subjects have integrated IT in assessment and also in teacher recruitment.

Balance and tension: The group maintained that balance and tension are unavoidable in curriculum development. Among dimensions that were considered were:

- on the one hand the speed of change of IT, and on the other the time needed for good curriculum development;

- on the one hand the changes created by IT and on the other the changes enabled/supported by IT. The group suggest that IFIP and WG3.1 should keep curriculum issues as a thread in all future conferences. 
The use of Cabri-Geometre was sited as an example.

Diffusion: A key issue is to convince or persuade teachers of the demonstrable effects of technology use. Hence the group identified the need for a system of dissemination of short synopses of programmes and models of integration, including failures as well as success stories. Here we present the first ideas for structuring such synopses, which should encourage people to appreciate the most promising ideas for their particular situation. In that respect, synopses should refer to fairly substantial works, involving at least one school and several teachers over a significant period of time. The contents of synopses might include:

- full references, aims, contents/age/subject area, resources (including particular backup), size/duration, finance/resources (how and where obtained);

- what were the successes?

- what were the failures?

- what would you do differently?

- what resources were used successfully?

\section{Focus Group: Teachers and Teaching}

\section{Participants}

Giorgio Casadei (I), Steffen Friedrich (D), Kurt Kreith (USA), Colette Laborde (F), Manoli Pifarré Turmo (I), Andreas Schwill (D)

Chair: Paul Nicholson (AUS)

Rapporteur: Paul Zorn (USA)

\section{Main issues}

The general focus was how IT changes the processes of teaching and learning. At first the group identified several very general roles that computers might play, including:

- amplification of thinking: providing such resources as "horsepower" and speed to the human mind;

- feedback, by monitoring processes and producing concrete outputs;

- helping students to acquire meta-cognitive skills, such as algorithmic thinking, information organization, knowledge transfer, process control;

- permitting multiple representations and manipulations of objects and ideas. 


\section{Key questions and some answers}

What do teachers need to know about IT in order to gain benefits mentioned above? They should

- understand general ideas behind any form of programming, but not necessarily details of coding programs in particular languages;

- understand a variety of IT tools, including word processors, spreadsheets and hypertext, so that they and their students can choose intelligently, and also understand the need for new tools;

- participate in developing educationally appropriate software, by being able to evaluate IT tools both as software and as educational resources;

- know whether and how IT fundamentally changes their own subject areas, for example how CABRI changes ways of doing and thinking about geometry;

- understand the pedagogical and didactic processes that various IT tools aim to address;

- recognize with their students when computers produce nonsensical or useless answers - output isn't meaningful just because a computer produces it.

What can we learn from past experience? For example, in Germany, technology-based language laboratories failed. Among the lessons from this experience are that teachers should be deeply involved and appropriately prepared; also that tools should be used for specific intellectual purposes. From hand held calculators we learn that although such machines can relieve burdens of routine computation, teachers need to know what else to do and how to use the new freedom such tools offer.

Calculators can now store data, and may be used in French high school examinations; French students now use calculators to store information for use during examinations. This means that teachers must re-think what to examine, and students must organize carefully the information they decide to store. However, experience with earlier technologies is not fully relevant to IT, because computers are qualitatively different from earlier tools. The computer can completely rearrange the relationships among student, teacher, and subject.

What is the teacher's role in an integrated IT environment? One effect is that teachers need especially to know how to manage, structure, and manipulate information sources, for example through hypertext environments. Teachers change from dispensers of information to moderators, catalysts, organizers, and synthesizers. Another effect is that teachers will need at least as good a knowledge of their subject areas as before though perhaps somewhat different knowledge. In-service teachers 
may need special help in coping with new IT environments and new teacher roles, especially in a time of rapid change.

How can teacher expertise be "multiplied" efficiently? Sharing expertise effectively is difficult because teachers are used to working alone. Close collaboration must be built in to systems. Teachers from different disciplines might learn from each other by collaborating on a single general project, such as building a hypertext environment to describe many aspects of a town.

\section{Focus Group: Managing integration 1}

\section{Participants}

Magda Bruin (NL), Hugh Burkhardt (GB), Maria Cabezas (E), Klaus Graf (D), Paul Jansen (NL), Cassandra Murphy (USA), Nathalie Saulnier (F), Matti Sinko (SF)

Chair: Jim Ridgway (GB)

Rapporteurs: Pieter Hogenbirk (NL), Viera Proulx (USA)

\section{Main issues}

We address the issues of organization, management, and implementation strategies for integration of information technology into secondary education. We start by identifying the key arguments for using information technology in schools. These arguments can be used to support decision makers at all levels: politicians, educational administrators, higher education, including teacher training institutions, business partners and parents, as well as classroom teachers.

IT integration should concern ways to support teachers in their central role, not simply to take over part of it. IT integration is not an end in itself; it is essential to identify key curriculum roles for IT in different subjects, and to identify elements of the curriculum that will profit most from integration. All our actions should be driven by questions about the quality of the learning activities which will result.

IT has penetrated the world of work in many different ways and also entertainment. These changes represent an important source of ideas about how innovation in education might be managed, and these societal changes are, themselves, justification for educational change associated with IT, and justify getting resources for IT. 
Principle level actors at all levels of the educational system need arguments they can use for integration of IT into schools. Some key points which can be used to convince politicians and administrators include:

- modern societies need to be increasingly 'smart' to survive economically;

- citizens who know nothing about technology are likely to become alienated in an increasingly technological society. This argument has important implications for access to IT by all groups, including those in economically deprived areas, and for females where activities may need to be designed to encourage them to use IT to the full;

- informed citizens need to understand the opportunities and threats which technology offers;

- the pressures for lifelong learning will require extensive use of IT;

- IFIP/UNESCO curriculum suggests we should do more;

- we need to prepare students for the workplace of the future;

- today, competency in using IT is as basic as reading;

To convince teachers to include IT in their teaching, several strategies can be employed:

- create a high quality IT based lessons that complement regular curriculum;

- include IT based activities into the existing 'high stakes' assessment, on which schools and teachers are judged, and provide curriculum materials needed to prepare for them;

- plan time and support for teachers' ongoing training and networking;

- create support centres with libraries of software and curriculum resources;

- aim to support weaker teachers.

\section{Organisational factors}

Politicians and administrators need to show their commitment to IT in policy statements that include specific targets to be attained over a period of time.

Co-ordination of IT activities at the school and district level should be done by teams that consist of:

- a senior teacher who can argue for resources with school management;

- an IT co-ordinator or teacher, knowledgeable in uses of IT in classrooms;

- a teacher who is an innovative teacher, but who may be IT naive. 
Co-ordinators should have ways to assess success, and plans on how they will remediate failures which are certain to occur. Plans should be made for continued teacher development and networking that include initial training, mutual classroom visits, regular support group meetings, networking with peers and mentors, learning about new resources, and working on shared projects. Sufficient time should be allocated for these activities, possibly by reorganizing class organization or time structure.

\section{Implementation level}

Planning for IT integration should be done on a long term basis. Plan funding for several years ahead: for hardware, software, curriculum materials, technical support, and upgrades. Select curriculum activities that can be implemented with the projected funding and have teacher's support.

Look for alternative ways of using IT in the classroom: group rather than individual projects; one computer in classroom as a teacher assistant or demonstration tool; use of older equipment and software for lower level activities; use of computer as a tool on occasional basis.

Support teachers in developing their own IT competencies and professional growth through:

- home computer use via equipment loans or discounts on purchase;

- easy access to computers at school;

- providing vivid examples of uses of IT in classroom - including pedagogy, lessons, classroom visits, videos;

- involving faculty and graduate students at local universities as partners and mentors who suggest curricular activities, help with development of class materials and lessons, and who provide examples of applications of IT at the leading edge of their discipline, providing support and assistance with subject specific problems. 


\section{Focus Group: Managing integration 2}

\section{Participants}

Lillian Cassel (USA), Jordi Castells Prims (E), Begoña Gros Salvat (E), John Mallatrat (GB), Mary Ann Robinson (USA), Josep Sales Rufi (E), John Scholtes (NL), Franz Stetter (D), Jacques Verwater (NL)

Chair: Margaret Niess (USA)

Rapporteurs: Mike Aston (GB), Ronald Ragsdale (CDN)

\section{Main issues}

Positive forces include skilled and enthusiastic teachers, successful models and dissemination, planning of innovation, demands of society and the creation and availability of software. Resistance emanates from reluctant teachers, short term views by governments, confusion between means and ends, curricula, schedules and examinations and the magnitude of the paradigm shift.

\section{A model for change}

The model proposed is learner centred and focusses on the school as the essential agent in the integration of technology in education. Although change needs to be effected within the school community, a recognition of strong links through subject disciplines with other local schools, and teachers, and even wider afield, needs to be amplified.

\section{The school}

The school requires a multi-faceted team led by teachers who are subject experts in the disciplines. They in turn are supported by the school principal, technical staff and curriculum assistants. Key features of the paradigm include the need to:

- plan new integration efforts based on the achievements and failures of successful models that are driving integration;

- utilize those skilled and enthusiastic teachers in the planning stages;

- provide reluctant teachers with opportunities to visit successful models, allowing time for reflection on their current pedagogical practices;

- have IT co-ordinators in the schools and provide them with good support and rewards;

- allocate finances in support of the sharing of ideas and experiences between teachers both within and outside the school and with other professionals within their disciplines;

- allow time for the organisational model to mature. 


\section{Outside school}

Appropriate agencies need to:

- describe activities that IT makes possible and document the importance in education, identify benefits to the discipline that might come from these new activities, and support specialists who need to validate benefits and state clearly how they can be realised;

- create a climate that encourages teachers to innovate;

- support wide-spread dissemination of successful innovations;

- support development of model sites, managed by skilled and enthusiastic teachers, giving access to other teachers to observe and validate;

- establish computer network contact between teachers where appropriate;

- improve the quality of pre-service and in-service teacher development by integrating the use of technology into teachers' courses in their disciplines;

- make available a resource directory to include sites to visit and reports on experiences;

- establish education programmes specifically for co-ordinators, including development of group motivation skills;

- establish partnerships among various stakeholders for implementation, innovation, and dissemination.

\section{Focus Group: Teachers as integrators}

\section{Participants}

Miguel Angel Aguareles (E), Francesca Alloatti (I), Krystyna Dalek (PL), Brian Durell (CDN), Karoly Farkas (ROM), Helene Godinet (F), Joyce Currie Little (USA), Pere Marques Graells (E), Anne McDougall (AUS), David Miller (GB), Joan Berga Reixach (E), Takashi Sakamoto (J), Robert Smith (USA), Seppo Tella (SF)

Chair: Anna Kristjansdottir (IS)

Rapporteurs: Charles Duchateau (B), Lilliam Hurst (CH)

\section{Main issues}

Today's school, through its organisation and preoccupations, has built many barriers, resulting in an isolated school. This may be represented as a gap between society in one circle and school in another. IT is one 
component which falls into the gap between these two circles for the learner.

If school is to remain a preserved environment for learning, it also has to open new vistas and to integrate perspectives coming from life outside school. Integration is the effort to provide an intersection between the school and society. An integrator-teacher is a teacher seeking topics and means which will enable school-linked preoccupations to intersect with the outside world. This could be represented by a merging across the gap of the two circles, and where they intersect IT is a component of reconciliation.

IT is not a name, but a means enabling the reconciliation of schools and society as well as removing the barriers inside schools as well as between school and society. Efforts should be made to create an environment in which teacher attitudes and beliefs can change. The end result should be a skilled, enthusiastic, and self- and peer-supporting team of teachers.

\section{Society}

Schools and integrated teachers need three new "Rs" from society: Rewards, Resources and Recognition. Rewards do not only consist of financial ones but society should recognize their work and initiative by providing necessary resources enabling them to continue their work of integration.

\section{School}

The culture and structure of today's school render the job of integrator-teacher and also the integration of IT very difficult. From a short-term viewpoint, and because of school structure and organisational constraints, a way of using IT capabilities can consist of fitting into the present-day structure a new entity. This is no longer a computer science course, nor really any existing classical subject, but is performing learning activities because of and around IT. This new entity will be devoted to real problem-solving originating in the present day situation of the learners outside the school.

The education of teachers involved in these new activities must be carefully charted and teacher trainees must be provided with teaching scenarios and appropriate tools. So, this may not be an excuse for non-integration of IT in other subjects and practices, but an opportunity for the teacher trainee, and even for the unconvinced teachers, to become aware of what IT is and how it can be used. 


\section{Intersection between school and society}

IT empowers average teachers to incorporate school activities into a virtual school concept which contains the symbiosis of a virtual school and the physical school, thus combining the virtual school with the real school.

\section{Teacher's attitudes, beliefs and preference}

Teachers have a central role in integrating IT into schools. They have to change their roles to become facilitators to help learners to use IT, which can be viewed as just another way to access knowledge. Thus, teachers' attitudes, beliefs and preferences have to be changed and adapted. We cannot fabricate this new teacher, only provide conditions for their emergence as well as support when they have emerged.

A good dissemination of IT is possible on the basis of one-to-one contacts and exchanges. The adoption of IT would also be made easier by integrating the need for using IT tools into existing curricula, and particularly by including IT features into assessment.

\section{Focus Group: Teacher education 1}

\section{Participants}

Norman $\mathrm{Au}(\mathrm{HK})$, Norbert Breier (D), Terry Cannings (USA), Sou-yung Chiu (TW), Giovanna Gazzaniga (I), John Gardner (GB), Csilla Heves $(\mathrm{H})$, Ferenc Iszaj $(\mathrm{H})$, Eva Kluge (D), Margaret Nagy (H), Mihaly Nagy (H), John Olson (CDN)

Chair: Frank (Nick) Nicassio (USA)

Rapporteurs: Fulvia Furinghetti (I), Brent Robinson (GB)

\section{Main issues}

In order for information technologies to be integrated into practice, ultimately teachers cannot be obliged to change but must instead come to an understanding of, and willingness to, alter their current practice. It is important therefore that any programme of change, personal or mandated from outside, includes a teacher education programme, and that this programme begins from, and respects, teachers' existing beliefs, assumptions, expectations, attitudes and needs. 
This applies to pre-service teachers as well as to serving teachers, though the nature of this mental set will vary between the two groups and of course, between individuals.

Proposals for technological education for teachers should therefore identify, acknowledge and build upon teachers' images of:

- the nature of their subject discipline;

- the teaching of that discipline;

- the technology.

Proposals for technological education for teachers must also relate to practical issues:

- pressure of time;

- the structure, administration and culture of the school;

- political compliance at a micro and macro level;

- expectations and needs generated by the wider society.

Often if we analyse the results of the implementation of externally motivated innovations, we cannot recognise the original intentions of the proposers. This happens because in the middle of this process there are teachers acting as filters between pedagogic proposals and classroom realities.

There is likely to be an inherent tension between:

- teacher educators' assumptions which are visions of what schools ought to be; and

- teachers' assumptions which are predicated upon a view of schools as they actually are or have been.

Teacher education should therefore include strategies for working with existing resources while fostering longer term vision.

It should also provoke the tensions which result from the interaction of the two and help teachers understand and cope with the nature of the change process, especially the move from a stable to an unstable state and the tensions and anxieties which may be felt.

Teachers need to be given concrete models of what can be achieved in terms of software applications, classroom activities and lesson planning. Teacher educators should:

- provide examples of effective classroom use of IT; and

- model the use in IT in their own teaching.

Teachers also need images of possibilities of what might be achieved. They need strategies for helping them to realise these possibilities. 
As part of their technological education, teachers should be encouraged to form collaborative groups in order to:

- reflect upon and develop their beliefs, assumptions, expectations, attitudes and needs in a dialectical process;

- generate action;

- provide mutual support to members in their role as change agents.

Teacher education for change and innovation also requires the education of policy makers. The principles and guide-lines in this paper must also be applied to this other important group if effective technological innovation is to succeed in education.

\section{Action priorities}

IFIP should identify, through a review of the literature and the promotion of research, what changes might be expected in classroom practice and of these changes, which exemplars should be actively pursued.

IFIP should also take steps to identify the strategies by which these desirable changes can be effected by teachers.

\section{Focus Group: Teacher education 2}

\section{Participants}

Anton van Aert (NL), Joan Escué Olivé (E), Akira Horiuchi (J), Dirk Janssens (B), M. Dolores Santandreu (E), Sigrid Schubert (D), Shigera Tsuyuki (USA), Joerg Vogel (D), Rado Wechtersbach (SO)

Chair: Wim Veen (NL)

Rapporteurs: Erich Neuwirth (A), Anthony Ralston (USA)

\section{Main issues}

The proper and increasing use of IT in secondary schools (and at other educational levels) depends upon a symbiosis between the supply side:

- innovators

- national programs

- researchers

- software developers; 
and the demand side:

- schools

- teachers

- students/parents

At present the demand side is rather weakly developed, as also is the national program aspect of the supply side. It is important that this weak development becomes stronger. This motivates the following general recommendations.

General Recommendation 1: In order to promote IT integration in education, appropriate steps need to be taken to stimulate demand for IT from teachers and schools and, as far as possible, also from parents and teachers.

This recommendation is echoed below in specific recommendations. On a somewhat less general level it is useful to delineate the various actors in the educational community:

- policy makers

- curriculum makers

- teacher educators

- schools/teachers

- students/parents.

Stronger links need to be established between various pairs of these actors. Of particular importance to this group is the link between teacher educators and schools/teachers. This leads to the second general recommendation.

General recommendation 2: Integrating IT into education requires close cooperation between teacher training institutions and the schools and teachers themselves.

\section{Recommendations for plans for action}

Teacher training institutions are playing a crucial role for any change in the educational system. So successful IT integration, in the long run, is simply impossible without a strategy for these institutions. In particular, the following factors have to be taken into consideration.

Partnership: Since IT integration is an ongoing process, not only teachers have to be trained, but feedback from schools to teacher training institutions can help to adapt the strategies of these institutions to the immediate needs of schools. Therefore partnerships between schools and 
teacher training institutions should be encouraged. Such partnerships should be fostered throughout the whole educational system.

Training the teacher trainers: Currently the IT awareness of teacher trainers seems to be the weakest spot with respect to IT in the educational system. Teacher trainers in general do not differ from school teachers as far as their beliefs and attitudes related to IT are concerned. Since with school teachers offering experience with computers as a personal tool enhancing productivity prove to be a main ingredient for successful IT integration in schools the same strategy should be applied for teacher trainers and teacher training institutions. Who should train those trainers? As in most teacher training institutions there are subject experts additionally having IT knowledge, peer learning seems to be the most viable strategy.

Train the student teachers: Student teachers should have experiences with IT during university studies in the following three different contexts:

- university departments should provide IT experience as part of the subject oriented studies;

- teacher educators should provide experiences with IT as a learning and teaching tool during the courses as well as during the internship;

- students should use IT as a personal productivity enhancement tool during their studies.

Train school teachers through partnerships: Ongoing in-service teacher training is a key issue for successful IT integration. As mentioned previously these training activities could be implemented within the framework of partnerships with teacher training institutions.

Involving teacher training institutions in policy activities: Teacher training institutions not only have the obvious task of training teachers, they also need to be involved in influencing curriculum changes software development creating supplementary educational material research. 